SILVA, C.R.A., COSTA, A.S. e SILVA, F.L. Reflexo de flêmen aspectos morfofisiológicos Revisão. PUBVET, Londrina, V. 5, N. 32, Ed. 179, Art. 1208, 2011.

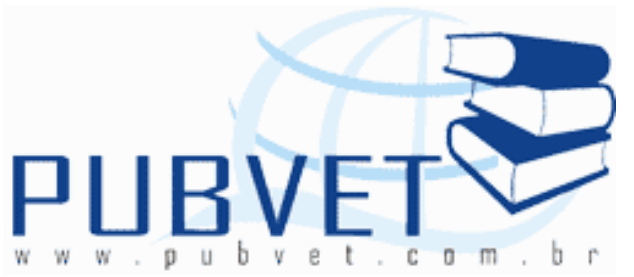

PUBVET, Publicações em Medicina Veterinária e Zootecnia.

\title{
Reflexo de flêmen aspectos morfofisiológicos - Revisão
}

Catarina Rafaela Alves da Silva ${ }^{1}$; Andréia da Silva Costa ${ }^{2}$; Francisco Lima Silva ${ }^{3}$

${ }^{1}$ Doutoranda em Ciência Animal-UFPI;

${ }^{2}$ Mestranda em Ciência Animal - UFPI;

${ }^{3}$ Professor Doutor Universidade Federal do Piauí.

\section{Resumo}

O Reflexo de Flêmen é um comportamento onde decorre da ondulação do lábio superior, no qual é uma característica bastante marcante em animais ungulados. Este tipo de comportamento está inteiramente interligado com a identificação sexual e acasalamento pelos machos em relação às fêmeas, sendo o órgão vomeronasal, responsável por este processo, através da identificação de feromônios pela urina da fêmea.

\section{Flehmen reflex morfofisiologics aspects - Review}

\section{Abstract}

The Reflex Flehmen is a behavior where result of curling the upper lip, which is a very marked characteristic of ungulates. This type of behavior is completely intertwined with sexual identification and mating by males compared to females, and the vomeronasal organ, responsible for this process by identifying the female pheromones in the urine. 
SILVA, C.R.A., COSTA, A.S. e SILVA, F.L. Reflexo de flêmen aspectos morfofisiológicos Revisão. PUBVET, Londrina, V. 5, N. 32, Ed. 179, Art. 1208, 2011.

\section{1-INTRODUÇÃO}

A reação Flêmen (do inglês flehmen), refere-se à elevação da cabeça e ondulação do lábio superior de animais, permitindo aos machos identificar as oportunidades de acasalamento por intermédio do seu órgão vomeronasal ou órgão de Jacobson (REECE, 2006).

Em outras palavras, o reflexo de Flêmen serve para direcionar moléculas em suspensão (feromônios) para dentro de um órgão vomeronasal, localizado na parte superior dos seios nasais, próximos ao cérebro. O vomeronasal transforma essas mensagens químicas em estímulos nervosos que serão interpretados pelo cérebro. Algumas dessas moléculas são liberadas especificamente próximas à ovulação e representam mensagens indicativas da receptividade sexual (HENRY, et al, 2009).

Desta forma, os feromônios femininos associados às secreções vaginais e urina durante o estro evocam esta resposta conhecida como Flêmen. Hafez (2003) descreve este reflexo como sendo um ritual onde o macho cheira a urina da fêmea e então levanta a cabeça com os lábios torcidos. Este comportamento é típico de bovinos e pode ser observado em muitas outras espécies, tais como gatos domésticos, cavalos, búfalos, tigres, antas, leões, girafas e caprinos.

De acordo com Lopes (2004), o reflexo de Flêmen constitui um evento fisiológico relacionado ao comportamento sexual de identificação (como a presença ou ausência de cio).

O comportamento sexual exerce um dos mais fortes controles do reino animal e usualmente dá prioridade sobre todas as outras formas de atividades do animal, como alimentação, descanso e sono (LOPES, 2004). É, portanto, indispensável à preservação das espécies e consta do conjunto de iniciativas e atitudes que implicam na realização da cópula e nos posteriores fenômenos de fecundação (HAFEZ, 2003). A característica do comportamento sexual pode ser influenciada por fatores como genética (machos de raça leiteira são mais ativos que os de corte), estação do ano, raça (zebuínos são mais vagarosos 
SILVA, C.R.A., COSTA, A.S. e SILVA, F.L. Reflexo de flêmen aspectos morfofisiológicos Revisão. PUBVET, Londrina, V. 5, N. 32, Ed. 179, Art. 1208, 2011.

que os da raça nelore), níveis hormonais, sanidade, manejo, dominância (o macho dominante executa a maioria das coberturas e restringe o desempenho de seus subordinados) e idade (SANTOS et al.,2006).

Os eventos fisiológicos do comportamento sexual podem ser agrupados em comportamento de identificação ou de reconhecimento, comportamentos de cortejo e acasalamento. Os comportamentos de reconhecimento e/ou identificação da fêmea em estro consistem nos eventos de cheirada ou lambida da vulva, cheirada ou lambida do corpo, acompanhamento da fêmea e reflexo de Flêmen. Já os comportamentos de cortejo ou pré- copulatórios são aqueles que testam a receptividade da fêmea e consistem nos eventos de reflexo de monta e frente a frente. Os eventos de acasalamento ou copulatórios consistem nos eventos de exposição de pênis, tentativa de monta, falsa monta (monta sem exposição de pênis), monta abortada (monta com exposição de pênis, porém não efetua a cópula) e serviço completo (LOPES, 2004).

\section{2- REVISÃO DE LITERATURA}

2.1- Feromonas: Comunicação por meios químicos

Sinais químicos são amplamente utilizados para comunicação social intra-específica em uma grande variedade de organismos vivos, indo de bactérias a mamíferos. Como exemplo, mamíferos secretam juntamente com a urina moléculas que promovem modulações neuroendócrinas, com alterações no comportamento e fisiologia do animal que recebe o sinal (BEHR, 2009). Cadelas no cio produzem uma secreção vaginal volátil que é perceptiva a um cão a quilômetros de distância. Porcos machos emitem pelas glândulas sub-maxilares substâncias odoríferas excretadas através da saliva e que provoca na fêmea um estado de paralisia, facilitando a cópula. Peixes, no momento da desova, nadam centenas de quilômetros em direção ao lugar que nasceram guiados por uma substância de natureza química ainda desconhecida, provavelmente exalada por seres mais jovens que ainda vivem no local de nascimento (FERREIRA et al., 2006). 
SILVA, C.R.A., COSTA, A.S. e SILVA, F.L. Reflexo de flêmen aspectos morfofisiológicos Revisão. PUBVET, Londrina, V. 5, N. 32, Ed. 179, Art. 1208, 2011.

A comunicação química entre indivíduos da mesma espécie tem muita semelhança com o sistema endócrino dentro do organismo de um indivíduo. Ambos utilizam mensageiros químicos que, mesmo em concentrações baixas, atuam via receptores específicos capazes de provocar respostas comportamentais e/ou fisiológicas. A distinção entre feromonas e hormonas reside no fato destas últimas serem libertadas internamente e exercerem influência sobre o metabolismo do indivíduo, enquanto que as primeiras são libertadas para o ambiente e influenciam indivíduos da mesma espécie (BRENHAS; SILVA, 2008).

Feromonas ou feromônios do grego pherin (transferir) e hormona (exalar), são sinais químicos produzidos por um organismo que, mesmo em pequenas quantidades influenciam o comportamento ou a fisiologia de outros indivíduos da mesma espécie. Constituem compostos orgânicos, geralmente voláteis e hidrofóbicos, que podem ser simples hidrocarbonetos ou incluírem grupos funcionais como alcoóis, aldeídos, cetonas, entre outros. São encontrados em quase todas as espécies do reino animal, invertebrados e vertebrados, os quais são similares na maneira que utilizam essa comunicação química. No reino animal, os feromônios tem importante papel no acasalamento e na delimitação do território de cada espécie, sendo que nos mamíferos os feromônios são liberados principalmente através de glândulas superficiais, na urina, fezes, saliva e suor ( BRENHAS; SILVA, 2008).

As feromonas podem ser classificadas quanto à resposta ao estímulo químico por ela produzido, como libertadoras ou indutoras. As feromonas libertadoras provocam resposta rápida e reversível exigindo ação imediata porém não muito duradoura, como as feromonas sexuais, de alarme e de demarcação territorial. As feromonas indutoras são aquelas que provocam alteração fisiológica no sistema endócrino ou reprodutivo (BRENHAS; SILVA, 2008).

Avanços tecnológicos recentes permitiram um aprofundamento no estudo de sistemas quimiosensórios e os aspectos que influenciam na fisiologia e comportamento de vertebrados, indicando que sistemas hormonais ativados 
SILVA, C.R.A., COSTA, A.S. e SILVA, F.L. Reflexo de flêmen aspectos morfofisiológicos Revisão. PUBVET, Londrina, V. 5, N. 32, Ed. 179, Art. 1208, 2011.

por feromônios exercem uma gama grande de funções neuroendócrinas no cérebro. O hipotálamo é uma das mais importantes regiões do cérebro, reconhecidamente envolvida no processamento de feromônios, possui conexão com muitas partes do SNC, incluindo o hipocampo,o núcleo amilóide,e os lobos frontais do córtex. Conhecido como o centro de controle das funções hormonais/ endócrinas, o hipotálamo controla em mamíferos diversos comportamentos sexuais, como a cópula e o reconhecimento sexual (BEHR, 2009).

O sistema nervoso de qualquer organismo pode ser modelado em sua forma mais simples como um sistema que possui entrada de dados (células receptoras), nenhum ou algum processamento do sinal (interneurônios) e um sistema de saída (células efetoras) (RODRIGUES, 2010).

As conexões neurais da via olfativa até o córtex sugerem que esse é um dos sistemas mais antigos dos animais, embora tal afirmação ainda esteja em discussão (RODRIGUES, 2010).

O sistema olfatório de animais desempenha um papel relevante na exploração do ambiente e no reconhecimento social e sexual de indivíduos. É através do sistema olfatório que os animais podem detectar e discriminar uma enorme quantidade de odorantes de estruturas químicas variadas e também as substâncias chamadas de feromônios, secretadas por animais da mesma espécie e que desencadeiam comportamentos sociais e reprodutivos inatos como, por exemplo, agressividade entre machos e acasalamento (SOUZA, 2008).

\subsection{Morfofisiologia do sistema olfatório}

O sistema olfatório consiste em um par de narinas (orifícios externos), orifícios internos (coanas), cavidade ou câmaras nasais, células receptoras, nervos olfatórios e bulbos olfatórios do cérebro (REECE, 2006). É formado por dois órgãos sensoriais localizados na cavidade nasal: o epitélio olfatório principal ( MOE - Main Olfactory Epithelium ) e o órgão vomeronasal (VNO- 
SILVA, C.R.A., COSTA, A.S. e SILVA, F.L. Reflexo de flêmen aspectos morfofisiológicos Revisão. PUBVET, Londrina, V. 5, N. 32, Ed. 179, Art. 1208, 2011.

Vomeronasal Organ) (SOUSA, 2008), sendo este último consististindo o sistema olfatório acessório, juntamente com o bulbo olfatório acessório que se encontra conectado à amídala, hipotálamo e córtex (CARETA, 2010).

O epitélio olfatório principal, do sistema olfatório principal, detecta um amplo e variado repertório de moléculas deodorantes fornecendo informações que permitem ao animal explorar o ambiente à sua volta, por exemplo, procurar comida e evitar substâncias venenosas (SOUZA. 2008). O bulbo olfatório principal, a amídala olfatória e o córtex olfatório também fazem parte deste sistema (REECE, 2006).

O órgão vomeronasal é o órgão sensorial que detecta os feromônios (SOUZA, 2008). Entretanto, esta idéia vem sendo contrariada por uma quantidade substancial de dados em que, embora os feromônios sejam detectados através do OVN, o sistema também responde a alguns produtos químicos que não os feromônios e alguns efeitos de feromônios são mediados pelo sistema olfativo principal ( GRONDONA, 2005).

O sistema olfatório principal possui um par de cavidades nasais divididos por um septo que é recoberto por um epitélio. Suas paredes laterais, consistem em cornetos cujo local se encontra o epitélio olfatório especializado. A área de superfície das microvilosidades e dos cílios da mucosa olfatória é enorme e pode ser maior do que a da superfície corporal total. A porção olfatória da mucosa nasal está quase toda confinada à região do corneto etmoidal e à porção oposta ao septo, sendo que as células olfatórias estendem - se através de toda a camada do epitélio olfatório, sofrem contínua renovação, tendo uma expectativa de vida de um há vários meses (REECE, 2006).

O sistema olfatório acessório está presente na maioria dos tetrápodes terrestres (GRONDONA, 2005). Caracteriza-se principalmente em receptores localizados no órgão vomeronasal - OVN (REECE, 2006), este órgão foi primeiramente descrito pelo anatomista dinamarquês Ludvig Jacobson, descrevendo - o em vários mamíferos, percebendo que em humanos havia a presença rudimentar desta estrutura (CARETA, 2010). 
SILVA, C.R.A., COSTA, A.S. e SILVA, F.L. Reflexo de flêmen aspectos morfofisiológicos Revisão. PUBVET, Londrina, V. 5, N. 32, Ed. 179, Art. 1208, 2011.

Possui estruturas pares em forma de charuto, com localização medial, na porção anterior do septo nasal. Este órgão possui uma abertura em um dos lados formando um saco cego em outro (REECE, 2006). O seu desenvolvimento e seu tamanho é bem relativo e variam substancialmente com a espécie, em humanos é pequeno de função indeterminada (SCHNEIDER et al., 2008). Em roedores situa-se dentro da cavidade nasal, em gatos, dentro do canal nasopalatino, o qual conecta as cavidades nasal e oral, em bovinos abre-se diretamente na cavidade oral (REECE, 2006).

Há pouco relatos sobre o órgão vomeronasal em mamíferos marsupiais, sendo alguns detalhados em gambá cinzento, mas que embora escasso, dados disponíveis indicam que há órgão vomeronasal em marsupiais aperfeiçoados para detecção de feromônios (SCHNEIDER et al., 2008).

Estudos embriológicos demonstram que o órgão OVN começa a se desenvolver em humanos, mas dissolve-se juntamente com o encapsulamento da cartilagem, bem antes do nascimento. Nossos parentes mais próximos (os macacos) também não o apresentam, o que não é particularmente invulgar, já que ele já apresenta funções diferentes (tais como a busca por alimentos) em jacarés, baleias, golfinhos e algumas salamandra (SMITH; BHATNSGARB, 1991)

O tecido receptor do órgão vomeronasal (OVN) situa-se na superfície medial do órgão bastante similar àqueles do sistema olfatório principal, com exceção aos cílios, apenas apresentando microvilos (REECE, 2006). Possui um sistema de bombeamento de moléculas para seu interior, através do lúmen, e depois bombeá-lo novamente para fora, para áreas circunvizinhas. Este mecanismo é controlado por eferentes vegetativos do nervo nasopalatino, sendo que uma lesão sofrida por este, o funcionamento normal do órgão vomeronasal é interrompido (REECE, 2006).

Os receptores do OVN são neurônios primários que se projetam diretamente para o bulbo olfatório. O bulbo olfatório acessório recebe impulsos provenientes do órgão vomeronasal e possui glomérulos distintos, onde 
SILVA, C.R.A., COSTA, A.S. e SILVA, F.L. Reflexo de flêmen aspectos morfofisiológicos Revisão. PUBVET, Londrina, V. 5, N. 32, Ed. 179, Art. 1208, 2011.

ocorrem sinapses dos nervos olfatórios com outras células localizadas dentro da estrutura (REECE, 2006).

O epitélio sensorial do vomeronasal consiste nos neurônios glutamatérgicos bipolares que emite seus dendritos apicais ao lúmen e seus axônios ao bulbo olfatório acessóro, localizados dorsocaudamente ao bulbo olfatório principal (CARETA, 2010).

A via vomeronasal se liga diretamente com as estruturas límbicas do cérebro que são importantes para o desenvolvimento e expressão de comportamentos primários motivados (comportamento sexual, agressivo e maternal) e é necessário para a ativação de vias neuroendócrinas envolvidas na reprodução (GRONDONA, 2005).

O bulbo olfatório acessório (BOA) é a primeira integração central do vomeronasal e possui diversas camadas, a camada plexiforme externa, sendo uma camada menor que a do bulbo olfatório principal e a camada glomerular, nas partes anteriores e posteriores do bulbo olfatório acessório recebe dendritos de diversas populações de células mitrais (CARETA, 2010).

No BOA, alguns neurônios são imunoreativos para alguns fatores de liberação hipotalâmicos, tais como LHRH, TRH e somastotatina, estes podem ser relacionados à participação de do bulbo olfatório acessório na resposta de ferormônios com modulação neuroendócrina e comportamental (CARETA, 2010).

2.3 - Fisiologia do Reflexo de Flêmen:

A palavra "reflexo" origina-se da palavra latina "reflectare", que significa "mover-se de volta". Pode ser definido como uma resposta involuntária e qualitativamente invariável do sistema nervoso a um estímulo (CUNNINGHAN, 2004).

O transporte de substâncias pelo OVN tem influência no comportamento em algumas espécies, incluindo principalmente ungulados e gatos (WEEKS et al., 2002), este tipo de comportamento denomina-se reação de Flêmen, caracterizado por uma "careta" facial realizada por estes animais, após a 
SILVA, C.R.A., COSTA, A.S. e SILVA, F.L. Reflexo de flêmen aspectos morfofisiológicos Revisão. PUBVET, Londrina, V. 5, N. 32, Ed. 179, Art. 1208, 2011.

percepção de líquidos, em particular na urina pelo órgão vomeronasal (OVN) (REECE, 2006), no qual destaca-se a principal função do reflexo de Flêmen, discriminação de odores do estro a partir da urina (WEEKS et al., 2002).

A urina alcança o orgão vômero-nasal a partir da cavidade bucal por meio dos ductos nasopalatinos que se abrem atras do "puvino dentário" dos ruminantes.

A ondulação do lábio superior fecha as narinas, e com a cabeça levantada, permite-se um diferencial de pressão que promove a passagem através dos ductos nasopalatinos até alcançar o órgão.

Todos os arcos reflexos possuem cinco componentes básicos, o receptor que transformam alguma forma de energia ambiental e a convertem em potenciais de ação através do nervo sensitivo. Assim que ocorre a captação, os potenciais de ação são gerados ao longo dos nervos sensitivos a uma freqüência proporcional à intensidade de energia transduzida; o nervo sensitivo (nervo aferente). Estes nervos conduzem potenciais de ação do receptor para o Sistema Nervoso Central (SNC), o terceiro componente é uma sinapse no SNC, o quarto componente é um nervo motor (nervo eferente) que conduz potenciais de ação do SNC para o órgão alvo (efetor ) e por fim o último componente é algum órgão alvo que executa a resposta reflexa. Sendo que se qualquer um desses componentes não tiverem um bom funcionamento, a resposta reflexa será alterada (CUNNINGHAM, 2004).

Desta forma, durante o Reflexo de Flêmen, os neurônios receptores do sistema olfatório acessório são seqüestrados dentro do OVN, longe do principal fluxo de ar dos principais neurônios receptores olfativos (MEREDITH, 1994). O tecido receptor do OVN em geral situa-se na superfície medial do órgão com epitélio semelhante ao sistema olfatório lateral. Os receptores são muito similares àqueles do sistema olfatório principal, com a exceção de que não tem cílios, mas microvilosidades. Esses receptores regeneram-se constantemente (REECE, 2006).

Esses receptores são neurônios primários que convertem os feromônios voláteis oriundos de líquidos corpóreos da fêmea (urina) em potenciais de ação 
SILVA, C.R.A., COSTA, A.S. e SILVA, F.L. Reflexo de flêmen aspectos morfofisiológicos Revisão. PUBVET, Londrina, V. 5, N. 32, Ed. 179, Art. 1208, 2011.

(REECE, 2006) que são transmitidos através de um caminho restrito, mas privilegiado, para as áreas do cérebro envolvidas com a reprodução e o comportamento social (bulbo olfatório acessório), contrastando com os neurônios do sistema olfatório principal que tem uma via ampla para cobrir vastas áreas do cérebro (MEREDITH, 1994). O bulbo olfatório acessório é, portanto, um sistema distinto em relação ao principal e ainda por vezes redundante em função (SMITHA; BHATNAGARB, 1991).

Um nervo motor (nervo eferente) conduz potenciais de ação do SNC para o órgão efetor (lábio superior) que executará, portanto, a resposta reflexa.

A ondulação do lábio superior fecha as narinas e, com a cabeça elevada, um diferencial de pressão promove a passagem ascendente através de ductos nasopalatinos para alcançar o órgão sensorial (REECE, 2006) para que então sejam identificados feromônios associados ao estro, o que permitirá aos machos identificar as oportunidades de acasalamento.

Em touros, a percepção de substâncias químicas pelos receptores do OVN em vacas na fase estrogênica usa a língua para comprimir o palato duro induzindo alterações de pressão do OVN (REECE, 2006) e fêmeas antílopes podem usar o Flêmen como sincronização de nascimento (ZAPICO, 1999).

\section{3- DISCUSSÃO}

Santos et al. (2006), estudando os parâmetros reprodutivos de bodes submetidos ao manejo de fotoperíodo artificial, observou a ocorrência de variações na freqüência de manifestação das características de cortejo (Flêmen, exposição da língua e do pênis) em animais de diferentes idades. Em todas as manifestações, verificou-se maior intensidade para os animais adultos, provavelmente em razão da experiência sexual, ocasionando maior tempo de reação, o que permitiu aos animais adultos testar a receptividade da fêmea em estro antes de realizarem a monta. Da mesma forma, a menor freqüência de manifestação dessas características nos animais jovens foi atribuída à maior avidez em realizar a cópula, ocasionando o menor tempo de reação. 
SILVA, C.R.A., COSTA, A.S. e SILVA, F.L. Reflexo de flêmen aspectos morfofisiológicos Revisão. PUBVET, Londrina, V. 5, N. 32, Ed. 179, Art. 1208, 2011.

Em um estudo sobre características reprodutivas e congelamento do sêmen de reprodutores das raças alpina e saanen submetidos ao manejo de fotoperíodo observou que animais jovens demonstraram maior libido que os adultos, considerando-se também um menor tempo de reação. Isto pode ser atribuído à menor experiência sexual e à maior excitação do animal jovem, que se estimulava (exposição de pênis, micção) antes de ser apresentado à fêmea em estro, estando neste caso, às atenções do animal mais voltadas para a realização da monta que para a exibição de comportamentos pré-coitais (SANTOS, 2001).

Sereno et al. (1996), em um estudo sobre o comportamento sexual do cavalo Pantaneiro em diferentes faixas etárias, em que se mantiveram em frente a uma fêmea em cio, observados uma vez ao dia durante 30 minutos, por três dias consecutivos, observaram que animais mais jovens (12 a 20 meses de idade) apresentaram menor freqüência de apresentação do reflexo de Flêmen quando comparado aos animais com maior idade ( 26 a 40 meses).

Em geral os animais mais jovens, ao entrar no curral de observação se aproximavam da fêmea em cio, esta apresentava atitudes agressivas afastando o macho e o mantendo a um raio de aproximadamente cinco metros. À tentativa de aproximação ultrapassando esta distância, a fêmea em cio reagia quase sempre com agressividade, sugerindo rejeição aos machos desta faixa etária.

Lopes (2009), durante estudo sobre avaliação andrológica por pontos e comportamento sexual de touros da raça Nelore, observou a precisão com o qual estes animais identificam as fêmeas em estro, apresentando uma alta freqüência dos eventos de cheirada ou lambida da vulva, reflexo de Flêmen e reflexo de monta. Estes eventos forma ainda mais intensos no período de manhã (6-12h), quando as fêmeas se encontravam na fase inicial do estro, mostrando assim forte interação com o período de duração do estro. A manifestação desses comportamentos sofreu redução com o decorrer do dia.

Bascuñan et al. (2008), analisando o comportamento sexual touros zebuíno(subespécie Bos indicus) e Angus (subespécie Bos taurus), em central 
SILVA, C.R.A., COSTA, A.S. e SILVA, F.L. Reflexo de flêmen aspectos morfofisiológicos Revisão. PUBVET, Londrina, V. 5, N. 32, Ed. 179, Art. 1208, 2011.

de coleta e processamento de sêmen, observaram que durante o processo de coleta de sêmen o tempo de reação de touros Angus foi menor que o dos touros zebuínos admitindo que estes são mais lentos em reagir a fêmeas em estro, o que indica a existência de diferenças de ordem genética no comportamento sexual desses animais.

Dias et al. (2009), durante avaliação do comportamento sexual 12 touros jovens (24 a 34 meses) Guzerá, sem experiência sexual, observados por 5, 10 e 15 minutos, observaram que os eventos com maior freqüência de manifestação foram os de identificação, principalmente os eventos de cheirar a região perineal e reflexo de Flêmen, independentemente do tempo de avaliação. Esta observação mostra a importância de tais eventos na manifestação do desejo sexual desses animais, sugerindo que estes eventos deveriam ser mais bem pontuados durante a realização de testes utilizados na avaliação do comportamento sexual de zebuínos, principalmente em touros jovens e sem experiência sexual.

Análise do comportamento em cavalos a partir da detecção dos ferormônios pela urina no período do estro e não-estro quanto à freqüência de cheiradas, latência, freqüência e duração do Flêmen em relação ao sexo e idade. Os potros apresentaram reação de Flêmen tanto quanto à urina do estro quanto a do não-estro, não foram encontradas diferenças significativas entre sexos quanto ao período de latência, a resposta pelo Flêmen e ao tipo de urina (WEEKS et al., 2002).

Em hipopótamo comum, em cativeiro foi observado reação de Flêmen em um macho 7 (sete) dias antes da apresentação do cio pela fêmea e 7 (sete) dias após cio, no qual o macho examinava a região anogenital e em seguida jogaria a cabeça para trás, ondularia seu bordo superior e exporia seus caninos ao mover suas maxilas, permanecendo nesta posição de 10 a 20 segundos, também podendo observar o mesmo comportamento após cheirar a urina da fêmea (ZAPICO, 1999).

Em marsupiais Tammar Wallaby, foram observados em machos após inspeção anogenital em fêmeas a retração do bordo superior e exposição dos 
SILVA, C.R.A., COSTA, A.S. e SILVA, F.L. Reflexo de flêmen aspectos morfofisiológicos Revisão. PUBVET, Londrina, V. 5, N. 32, Ed. 179, Art. 1208, 2011.

dois primeiros incisivos, não havendo levantamento da cabeça (SCHNEIDER et al., 2008).

Quanto aos felinos existem pouco relatos sobre a comunicação química em espécies selvagens de grande porte, especialmente as ameaçadas de extinção. Pode-se citar o comportamento do gato doméstico, considerado modelo para estudo da família Felidae, uma vez como muitos mamíferos, com exceção aos primatas, possuem o bulbo olfativo acessório, o órgão vomeronasal, conectado à cavidade oral, a apresentação do reflexo de Flêmen ocorre ao levantar o lábio superior e manutenção da boca aberta por alguns segundos para detecção do odor (GUANDOLINI, 2009).

\section{CONSIDERAÇÕES FINAIS}

O reflexo de Flêmen se dá por uma resposta à urina excretada por fêmeas em estro da mesma espécie após a inspeção anogenital. É um comportamento bastante observado em mamíferos principalmente exibido por alguns felídeos e pela maioria dos ungulados, caracterizado pela abertura da boca e retração do bordo superior dando forma de uma careta.

O órgão mais comunmente envolvido é faz parte do sistema olfatório acessório no qual inclui o órgão vomeronasal e bulbo olfatório.

A maioria dos mamíferos possui um órgão vomeronasal aperfeiçoado que podem sofrer adaptações durante a evolução das espécies e aos diferentes sinais e comportamentos sob efeito dos feromônios.

Existem controvérsias quanto à idade e tipo de urina para a reação de Flêmen, não sendo observada esta diferença entre os sexos.

Podem existir comportamentos de reação de Flêmen em fêmeas, não com o intuito de reprodução e acasalamento, uma vez que o órgão vomeronasal não é sensível somente aos ferormônios .

Os feromônios são importantes para o comportamento sexual e o controle endócrino reprodutivo dos mamíferos. 


\section{REFERÊNCIAS BIBLIOGRÁFICAS}

BASCUÑAN, D.S.R.; JORGE, A.M.; ROCHA, G. P.; WESCHLER, F. S.; ANDRIGHETO,C.

Comportamento sexual de touros zebuínos e Angus em central de coleta e processamento de

sêmen, Revista Brasileira de zootecnia, v. 37. № 2, p. 254-260, 2008. Disponível em:

www.sbz.org.br.

BEHR, G.A. Exposição curta a feromônios de ratos machos diminui a ansiedade e atividade locomotor - exploratória e modula o perfil redox do sistema nervoso central e trato de fêmeas virgens. Porto Alegre, 2009. Tese. Universidade Federal do Rio Grande do Sul, Porto Alegre, 2009

BRENHAS, M.J.; SILVA, C.S. Feromonas: comunicação por meios químicos. Revista da Faculdade de Ciência e Tecnologia, n 5, pág. 54 - 61, 2008http://hdl.hondle.net/10284/951.

CARETTA, C.M. The rodent accessory olfatory sistem. Journal of Comparative Phisiology A. v.196.p. 767-777, 2010.

CUNNINGHAM, J.G. Tratado de Fisiologia Veterinária , $4^{\circ}$ edição, Rio de Janeiro;

Guanabara Koogan, 2004.

DIAS, J.C.; ANDRADE, V.J.; EMERICK, M.A. Teste da libido em touros jovens guzerá e suas associações com características reprodutivas e níveis séricos de testosterona. Archives of Veterinary Science, V. 14, n4, p. 204-213, 2009

FERREIRA, E.; POMBINHO, J.; TACANHO, J.P.; CERQUEIRA, M.M.; RIBEIRO,T. Feromonas. Lisboa, Portugal, Universidade_Lusófona de Humanidade e Tecnologias, 6p. Disponível em: http:// paginas.ulusófona.pt/p415/623- Feromonas-f1.pdf.

GRONDONA, K.E.B. Morfometria do órgão vomeronasal em ratos adultos. São Paulo, 2005. 100p.Dissertação mestrado.Faculdade de Medicina Veterinária e Zootecnia de São Paulo. São Paulo, 2005.

GUANDOLINI, G.C. Enriquecimento ambiental para gatos domésticos (Felis Silvestris catus L.): A importância dos odores. Ribeirão Preto, 2009. 66p. Dissertação Mestrado. Universidade de São Paulo. São Paulo, 2009.

HAFEZ, B.; HAFEZ, E.S.E. Reprodução Animal , 70 Ed. Barueri, SP, Editora: Manole, 2003.

HENRY, M.; LAGO, L.A.; MENDONÇA, L.F. Asininos: animais com características sociais e reprodutivas próprias. Revista Brasileira de Reprodução Animal, Belo horizonte, v.33, n.4, p.223-230, oct / dez, 2009. Disponível em : www.cbra.org.br.

LOPES, F.G. Avaliação andrológica por pontos e comportamento sexual de touros da raça nelore ( Bos taurus indicus ), Viçosa, Minas Gerais, 2004. Tese.

MEREDITH, M. Sensory processing in the main and accessory olfactory systems: comparisons and contrasts. Neurociência, v. 60, n 2, pag. 463-468, 1994.

REECE, W.O. Dukes Fisiologia dos Animais Domésticos, $12^{\circ}$ Ed. Rio de Janeiro, RJ, Editora: Guanabara Koogan, 2006. 
RODRIGUES, F.V. Fisiologia sensorial. Revista da Biologia, v. 05, 2010. Disponível em: www.ib.usp.br/revista.

SANTOS, A.D.F. Características reprodutivas e congelamento de sêmen de reprodutores das raças alpina e saanen submetidas ao manejo de fotoperíodo. Viçosa, 2001. Tese. Minas Gerais, 2001.

SANTOS, A.D.F.; TORRES, C.A.A.; FONSECA, J.F.; BORGES, A. M.; COSTA, E.P.; GUIMARÃES, J.D.; ROVAY, H. Parâmetros reprodutivos de bodes submetidos ao manejo de fotoperíodo artificial, Revista Brasileira de Zootecnia, v.35, n 5, p. 1926-1933, 2006. Disponível em: www.sbz.org.br.

SCHNEIDER, N.Y.; FLETCHER, T.P.; SHAW, G.; RENFREE, M.B. The vomeronasal organ of the tammar wallaby. Journal of anatomy. v. 213, p.93-105, 2008.

SERENO, J.R.B.; MELO, M.J.V.; HENRY, M.R.J.M.; CASSAL, G.D. Estudo do comportamento sexual de eqüinos da raça pantaneira no período peripuberal. Comunicado TécnicoEmbrapa, n 18, 1996.

SMITH, T.D.; BHATNAGARB, K.P. Vomeronasal System Evolution. Journal of Biochemistry and Molecular Biology, vol.39, n 4, pages 601-614, 1991.

SOUZA, J.M. Análise das regiões produtoras dos genes de receptores olfatórios e de receptores de feromônios do tipo 1. São Paulo, 2008.Tese.

WEEKS, J.W.;CROWELL-DAVIS, S.L.; HEUSNER, G. Preliminary study of the development of the Flehmen response in Equus caballus. Applied Animal Behaviour Science. v. 78, p. 329335, 2002.

ZAPICO, T.A. First documentation of Flehmen in a Common Hippopotamus (Hippopotamus amphibius). Zoo Biology. v. 18, p.415-420, 1999. 